\title{
Effect of training and supportive supervision on knowledge and practice of integrated diseases surveillance and response among primary health care workers in Kano State, Nigeria
}

\author{
Usman Sunusi Usman, ${ }^{1,2}$ Abubakar Muhammad Kurfi, ${ }^{3}$ Yusuf Abdu Misau, ${ }^{4,5}$ \\ Umar Lawal Bello, ${ }^{6}$ Aliyu Muhammad Maigoro, ${ }^{1}$ Adam Ibrahim Abdullahi ${ }^{1}$
}

${ }^{1}$ Department of Public Health, Faculty of Basic Health Sciences, Bauchi State University, Gadau, Nigeria; ${ }^{2}$ Department of Public Health, Federal Medical Centre Birnin, Kudu, Nigeria; ${ }^{3}$ National Health Insurance Scheme, Kaduna Zonal Office, Nigeria; ${ }^{4}$ Department of Community Medicine, Abubakar Tafawa Balewa University of Technology, Bauchi, Nigeria; ${ }^{5}$ Department of Epidemiology and Biostatistics, School of Public Health, College of Medical Sciences, Mount Kenya University, Kenya; ${ }^{6}$ Department of Nursing Sciences, College of Health Sciences, Bayero University Kano, Nigeria

\begin{abstract}
Communicable diseases continue to be major causes of, morbidity, mortality and rising health-care costs especially in developing countries. Integrated Diseases Surveillance and Response (IDSR) strategy was endorsed by Nigeria in 1998, as a means of strengthening communicable disease surveillance and response in order to make it more sensitive at all levels of government. A quasi-experimental study design was used to assess the effect of training and supportive supervision on knowledge and practice of IDSR among Primary Health Care (PHC) workers. Data was col-
\end{abstract}

Correspondence: Usman Sunusi Usman, Department of Public Health, Federal Medical Centre, Birnin Kudu, Jigawa State, Nigeria.

Tel.: +08037601861

E-mail: usugwarzo@gmail.com

Key words: IDSR, PHC workers, training and supportive supervision.

Contributions: USU, contributed in the design, analysis and interpretation of data as well as drafting the article for intellectual content; AMK, contributed in the analysis, discussion and interpretation of data, also revised the article critically; YAM, participated from conceptualization of the research ideas up to analysis and interpretation of research findings, also participated in drafting the articles for intellectual content; ULB, contributed in the analysis, discussion and interpretation of data; $\mathrm{AM}$, contributed in the analysis, discussion and interpretation of data; IA, contributed in the analysis, discussion and interpretation of data, also revised the article critically.

Conflict of interest: the authors declare no conflict of interest.

Funding: none.

Received for publication: 1 June 2018

Revision received: 14 October 2018.

Accepted for publication: 14 October 2018.

This work is licensed under a Creative Commons Attribution NonCommercial 4.0 License (CC BY-NC 4.0).

(C) Copyright U.S. Usman et al., 2018

Licensee PAGEPress, Italy

Annals of African Medical Research 2018; $1: 30$

doi:10.4081/aamr.2018.30 lected using an interviewer-administered questionnaire, and analyzed with the aid of Epi info version 3.5.3. Statistical significance was set at $\mathrm{P}<0.05$. The mean knowledge score of IDSR at baseline was $28.9 \pm 9.7$ in the study and $27.4 \pm 10.5$ in the control group. However, after the intervention, it improved to $51.3 \pm 11.8$ in the study and slightly changed to $27.1 \pm 10.6$ in the control group $(\mathrm{P}<0.05)$. While, with regards to practice of IDSR, the mean practice scores improved in the study group from $6.43 \pm 1.25$ to $16.37 \pm 3.86$ after intervention $(\mathrm{P}<0.05)$. In the control group, however, the mean practice score changed from $6.89 \pm 1.36$ to $8.45 \pm 2.75(\mathrm{P}<0.05)$ at the end of the study. The proportion of some IDSR core activity and supportive function changed from $0 \%$ and $16.6 \%$ to the standard benchmark of $80 \%$. Training and retraining of health workers on IDSR were recommended as well as periodic supportive supervisory approach in order to enhance health workers capacity.

\section{Introduction}

Disease surveillance is a critical component of the health system in generating essential information for optimal health care delivery. ${ }^{1-3}$ The World Health Organization (WHO) has been making continuous efforts in developing and strengthening disease surveillance during the last three decades; Information on surveillance is essential for appropriate responses and actions by public health authorities in charge of disease prevention and control. , $^{2,5}$

Essentially, the surveillance activities are very dynamic and form an integral part of any health care delivery system., Incorporating priority diseases of public health importance, removing non-priority ones according to change in the epidemiological pattern, and availability of cost-effective interventions as well as resources is highly needed. ${ }^{6}$ The modern trend is moving towards establishing an integrated disease surveillance system. ${ }^{4-5,7}$ Such an approach ensures sustainability, enhances accessibility and reduces cost. It also envisages all surveillance activities in a country as a common public service, which carries out many functions using similar structures, processes and personel. ${ }^{8}$

The IDSR is a process of coordinating, prioritizing, and streamlining of multiple disease surveillance systems into a unified national disease surveillance system that combines core surveillance activities and support functions into a single integrated activity. 6,9 The main purpose of IDSR is to make the health system more efficient and effective in providing timely, accurate and relevant information for action. ${ }^{10}$ The IDSR strategy was developed by 
the Africa Regional Office (AFRO) of WHO. ${ }^{5}$ The goal was to build WHO/AFRO countries' capacity to detect, report and effectively respond to priority infectious diseases. ${ }^{5}$ In September 1998 , during the $48^{\text {th }}$ WHO Regional Committee for Africa, member States unanimously adopt IDSR as their strategy for strengthening national surveillance systems. ${ }^{4-6,11}$ In 1998, Nigeria along with other member nations at meeting in Harare, endorsed the IDSR strategy as a means of strengthening communicable disease surveillance and response with a view to making it more sensitive at all levels. ${ }^{5}$

In order to improve the effectiveness of IDSR strategy, a monitoring and evaluation system was incorporated. ${ }^{2,3,12,13}$ Data are collected, analysed, and interpreted on a weekly, monthly, or quarterly basis by facility and district staff and used to identify areas that require strengthening. 6,14 Several indicators are used to measure progress towards achieving an overall program target. ${ }^{14,15}$ These focus on reporting, data quality, and quality of investigation and response, and system functioning. ${ }^{6,15}$

Periodically, once a month, weekly, quarterly or annually, the health facilities summarize the number of cases and deaths for each routinely reported IDS condition and report the totals to the district. ${ }^{4}$ The health facility performs some analysis of the data such as keeping trend of selected priority diseases or conditions and observing whether certain thresholds are passed to alert staff to take action. ${ }^{4,6,7}$ One action that is taken if an outbreak is suspected is to obtain laboratory confirmation. ${ }^{7}$

During the epidemic of meningitis in Burkina Faso in 2002, integration between laboratory and surveillance was developed. And, it is through a national laboratory that, contrary to all expectations, the confirmation of the implication of the W135 strain in the epidemic has been established, changing forever the profile of the epidemic meningitis in Burkina Faso and the meningitic belt. ${ }^{16}$ While in Ghana, early detection and laboratory confirmation of a meningococcal meningitis outbreak using IDSR indicators prompted the rapid implementation of a meningococcal vaccination campaign in the Bolgatanga district of northeast Ghana in November, 2002.11

While there has been significant progress in surveillance activities through the implementation of IDSR, much of the important work has taken place at the national level in Burkina Faso, Ethiopia, Ghana, Mali, Uganda, Southern Sudan and Nigeria. ${ }^{4,5,11}$ A critical goal and major remaining challenge is bringing these guidelines to the peripheral levels. Meanwhile, where IDSR training was conducted, there is a need to regularly supervise the trained personnel, and to evaluate the performance of the surveillance system by using IDSR core indicators. Informal opportunities for on-site training should be taken wherever possible. ${ }^{11}$

In a study conducted by Bawa et al. on effect of training on the reporting of notifiable diseases among health workers in Yobe state, Nigeria. ${ }^{15}$ The proportion of personnel who were aware of the surveillance system increased from $35.6 \%$ to $91.9 \%$. ${ }^{15}$ The percentage completeness was $2.3 \%$ before and $52.0 \%$ after, while the percentage timeliness was $0.0 \%$ before and $42.9 \%$ after in the experimental group. It was concluded that training had a positive effect on health personnel knowledge, reporting requirement and the timeliness and completeness of the disease surveillance and notification system. ${ }^{15}$

Supportive supervision is recognized as critical part of human resource management for the delivery of quality health care services. ${ }^{17,18}$ Some of the benefits of supportive supervision include: helping service providers to achieve work objectives by improving their performance, ensuring uniformity to set standards, identifying problems and solving them in a timely manner, making a fol- low-up on decisions reached during previous supervision visit, identifying staff needs and providing opportunities for personal development and reinforcing administrative and technical link between high and lower levels. ${ }^{19}$

\section{Materials and Methods}

The study was conducted among health care workers in Gwale and Tarauni LGA of Kano State. A quasi-experimental study design was used comparing the study and control groups (training and supportive supervision) in the study group.

One hundred and sixty-three questionnaires were administered to each group of participants at baseline. While, during post-intervention a total of 151 and 153 participants from the intervention and control LGAs completed the interviews.

A multistage sampling method was used to administer the questionnaires through the guidance of researcher and research assistants as follows:

Stage 1: Two local Government Areas (LGAs) were randomly selected from the total of 44 LGAs in Kano State by balloting. The selected LGAs were thereafter randomly allocated into intervention (Gwale) and control (Tarauni).

Stage 2: In the second stage, all the PHC facilities in the intervention and control LGAs were listed. Twelve health facilities from the intervention and control LGA were randomly selected through balloting.

Stage 3: This involved selection of respondents at health facility level by systematic sampling.

A semi-structured interviewer administered questionnaire, consisting of 3 sections (A to C) was used for data collection in the study. The questionnaire was developed by the researcher with the aid of National Technical Guidelines for IDSR. ${ }^{4-6}$ Section A of the questionnaire sought information on respondents' bio data, and section $\mathrm{B}$ elicited information on knowledge of IDSR while section $\mathrm{C}$ asked questions regarding respondents' practices of IDSR.

Baseline data was collected from the potential respondents in both intervention and control LGAs using the study questionnaire. After the baseline data collection, the selected participant in the study group were trained for five days by the researcher and support staff/research assistants on the basic principles and functions of IDSR. The training adopted and used the technical guidelines for IDSR in Nigeria developed by the FMOH. ${ }^{4}$ After six months following training on IDSR and supportive supervision in the study group, all the selected health workers who participated in this study from both intervention and control facilities were served with another set of the same study questionnaires to generate the post-intervention data.

The outcome variable measured was the percentage change in the mean score on knowledge and practice of IDSR: Each correctly answered question on knowledge earned one mark. The maximum score on knowledge was 70 . Scores below or equal to 35 $(<50 \%)$ were graded as poor knowledge in IDSR while 36 scores and above $(\geq 50 \%)$ were graded as good knowledge on IDSR. While, each correctly answered question on practice earned one mark. The maximum score on practice was 25 . Scores below or equal to $12.5(<50 \%)$ were graded as poor practice while 12.6 scores and above $(\geq 50 \%)$ were graded as good practice of IDSR. The scores earned were graded as in a previous study. ${ }^{17}$ All the data generated from the study was analyzed using Epi info version 3.5.3. Categorical data was presented as percentages, while quantitative data was presented using mean and standard deviation as appropriate. Student't test was used to compare mean scores in 
knowledge and practices of IDSR between the study and control groups at baseline and at post-intervention. Percentage difference in knowledge and practices of IDSR among health workers was calculated between post-intervention and pre-intervention values. Chi-square test was used to determine significant association between categorical variables. A P-value of $\leq 0.05$ was considered significant. Ethical clearance was obtained from the ethical committee of Aminu Kano Teaching Hospital before commencement of the study. The provisions of the HELSINKI declaration were respected. A written permission was obtained from the local government PHC departments of both intervention and control LGAs.

\section{Results}

The mean age of respondents in the study and control LGAs were $38.4 \pm 7.9$ and $39.6 \pm 8.5$ years respectively. PHC workers in the age group 30-39 years had the largest representation in both the intervention (37.4\%) and control (38.0\%) LGAs. Majority of the workers in both intervention (38.7\%) and control (42.3\%) LGAs were CHEWs: others included $\mathrm{CHO}$, Medical Laboratory Technologist/Scientist, Medical record officers as well as Nurses/ Midwives. About two-thirds $62 \%$ and $60.7 \%$ of the workers in the respective groups were married, and majority were males with sex ratio of 1.8:1 in the intervention LGA and 2.0:1 in the control LGA (Table 1).

The level of aggregate knowledge scores of IDSR among PHC workers in the study and control groups was compared at baseline. In the study group, $38.0 \%$ had good knowledge, while $39.3 \%$ had good knowledge in the control group. This difference was not statistically significant $(\mathrm{P}>0.05)$ between the two groups at baseline. While, the mean knowledge score at baseline was $28.9 \pm 9.7$ in the intervention LGA and $27.4 \pm 10.5$ years in the control LGA. There was no statistically significant difference in the mean knowledge score between the study and control group $(\mathrm{t}=1.23, \mathrm{df}=324$, $\mathrm{P}=0.231)$ (Table 2). About a quarter each $(25.8 \%$ in study group and $28.2 \%$ in control group) had good practices scores for IDSR. While, majority $(74.2 \%$ in study group and $71.8 \%$ in control group) had poor scores at baseline. There was no statistically significant difference $(\mathrm{P}=0.618)$ between study $(25.8 \%)$ and control $(28.2 \%)$ groups in term of practice grade of IDSR at baseline. The mean practice score at baseline was $6.43 \pm 1.25$ in the intervention LGA and $6.89 \pm 1.36$ in the control LGA. There was no statistically significant difference in the mean practice score between the study and control group $(\mathrm{t}=0.89, \mathrm{df}=324, \mathrm{P}=0.110)$ (Table 3 ).

After intervention, PHC workers' knowledge of IDSR

Table 1. Socio-demographic characteristics of participants in study and control group.

\begin{tabular}{|c|c|c|c|c|}
\hline Variable & Study group & Control group & $\chi^{2}$ & P-value \\
\hline $\begin{array}{l}\text { Age group } \\
20-29 \\
30-39 \\
40-49 \\
50-59 \\
\text { Mean age } \pm \text { SD }\end{array}$ & $\begin{array}{l}33(20.2) \\
61(37.4) \\
50(30.7) \\
19(11.7) \\
38.4 \pm 7.9\end{array}$ & $\begin{array}{l}30(18.4) \\
62(38.0) \\
45(27.6) \\
26(16.0) \\
39.6 \pm 8.5\end{array}$ & 1.50 & 0.68 \\
\hline $\begin{array}{l}\text { Gender } \\
\text { Males } \\
\text { Females } \\
\end{array}$ & $\begin{array}{l}104(63.8) \\
59(36.2)\end{array}$ & $\begin{array}{l}109(66.9) \\
54(33.1)\end{array}$ & 0.34 & 0.56 \\
\hline $\begin{array}{c}\text { Marital status } \\
\text { Married } \\
\text { Others }\end{array}$ & $\begin{array}{l}101(62.0) \\
62(38.0)\end{array}$ & $\begin{array}{l}99(60.7) \\
64(39.3)\end{array}$ & 0.01 & 0.91 \\
\hline $\begin{array}{l}\text { Professional category } \\
\text { CHEW } \\
\text { CHO } \\
\text { Nurse/Midwives } \\
\text { Medical Record Officers } \\
\text { Laboratory Scientist } \\
\text { Others }\end{array}$ & $\begin{array}{l}63(38.7) \\
11(6.7) \\
26(16.0) \\
19(11.7) \\
17(10.4) \\
27(16.5)\end{array}$ & $\begin{array}{l}69(42.3) \\
10(6.1) \\
23(14.1) \\
20(12.3) \\
20(12.3) \\
21(12.9)\end{array}$ & 1.52 & 0.91 \\
\hline
\end{tabular}

Table 2. Aggregate knowledge scores for IDSR among the participants at baseline.

\begin{tabular}{lcc} 
Level of knowledge of IDSR & Study group (\%) Control group (\%) \\
Good & $62(38.0)$ & $64(39.3)$ \\
Poor & $101(62.0)$ & $99(60.7)$ \\
\hline Total & $163(100.0)$ & 126 \\
\hline
\end{tabular}

Table 3. Aggregate practices scores of IDSR among the study and control group at baseline.

\begin{tabular}{lcccc} 
Practice score & Study group frequency (\%) & Control group frequency (\%) & Total \\
Good & $42(25.8)$ & $46(28.2)$ & 88 \\
Poor & $121(74.2)$ & $117(71.8)$ & 238 \\
\hline Total & $163(100)$ & $163(100)$ & 326 \\
\hline
\end{tabular}

$\chi^{2}=0.25, \mathrm{df}=1 \mathrm{P}=0.618$ 
increased from baseline level of $38.0 \%$ to $82.1 \%$ post intervention in the study group. This difference was statistically significant $(\mathrm{P}<0.05)$. While, in the control group there was only slight increase in the aggregate knowledge score from $39.3 \%$ at baseline to $41.2 \%$ post-intervention (Table 4).

Furthermore, PHC workers' practice of IDSR increased from baseline level of $25.8 \%$ to $63.6 \%$ post intervention in the study group. This difference was statistically significant $(\mathrm{P}<0.05)$. While, in the control group there was only slight increase in the aggregate practice score from $28.2 \%$ at baseline to $35.9 \%$ postintervention. Meanwhile, the mean practice scores increased for the study group from a baseline level of $6.43 \pm 1.25$ to $16.37 \pm 3.86$ after intervention. These statistically significant differences $(\mathrm{P}<0.05)$ were however not demonstrated in the control group. In the control group, where there was no training and supportive supervision, however, the mean practice score at baseline marginally increased from $6.89 \pm 1.36$ to $8.45 \pm 2.75$ at the end of the study. While, the aggregate good practice scores of IDSR in the study group increase from $25.8 \%$ at baseline to $63.6 \%$ at postintervention, that of the control group marginally increase from $28.2 \%$ at baseline to $35.9 \%$ at post-intervention (Table 5).

\section{Discussion}

Few studies have assessed health workers general knowledge on diseases surveillance and most have assessed their knowledge on components of diseases surveillance such as knowledge of notifiable diseases notification, data collection and information transmission, and functional status of DSN among health workers. ${ }^{17,20-}$ 22

The baseline mean and aggregate knowledge scores among study and control group in this study were higher than what was earlier reported in Yobe. ${ }^{17}$ Knowledge of IDSR among health care workers was found to be $57.7 \%$ and $62.0 \%$ in both the study and control group respectively; this is slightly higher than findings by Bawa et al. who reported $38.2 \%$ had good knowledge of DSN. This contrasted the findings by Ofilli et al., who reported that only $11.9 \%$ of doctors studied had good knowledge of DSN. ${ }^{12}$ This could be due to difference in the two study populations, as the former comprised of all professional category of health workers, while the later comprised of only doctors. This showed that lack of knowledge of reporting requirements seems to be a major factor affecting IDSR. ${ }^{17,20,21}$ Also, this finding is lower than the findings by Nnabue et al. who reported that $89.8 \%$ of the health workers were aware of DSN. ${ }^{22}$

With regards to practice of IDSR, rapid notification of infectious diseases is essential for prompt public health action and for monitoring of disease trends at the local, state and national levels. ${ }^{12,15}$ Despite its importance, notification suffers from some setbacks, as shown by several studies. ${ }^{22-24}$ On the practices of IDSR, $28 \%$ in the study and $38 \%$ in the control group had ever reported IDSR priority diseases from the health facilities. This finding was slightly higher than that of Bawa et al. in which they found out that $27.1 \%$ had ever reported notifiable diseases. ${ }^{15}$ But, this finding was much lower than that in Taiwan whereby $83.5 \%$ of doctors had experience of reporting notifiable diseases. ${ }^{26}$ Some of the reasons for not completing the forms identified in the study include; lack of knowledge on diseases under surveillance, IDSR forms have many questions and lack of time to complete the forms. But, previous studies have attributed poor reporting to lack of adequate forms and training on diseases surveillance and notification. ${ }^{17,22}$

Functional communicable diseases surveillance provides data for monitoring and assessing trends of diseases over time, which is important for prevention and control. ${ }^{17,20,21,27}$ It is a key for priority setting as it shows the disease burden. In addition, it is a key principle for early detection of outbreaks. ${ }^{16-18}$ Standard case definitions were available in English only and were regularly used by three $(25 \%)$ health facilities in the study LGA and four $(33.3 \%)$ in the control LGA. This was similar to findings in Tanzania ${ }^{24}$ by Mghamba but much lower than the findings by Abubakar AA in Kaduna State, Nigeria. ${ }^{13}$ In Ghana, standard case definitions pamphlets were distributed to health facilities for diagnosis, this increased the availability and use of case definitions at health facilities. ${ }^{7}$ With regard to data analysis and interpretation, it needs to be done at all levels of disease surveillance right from community to national and international levels. ${ }^{8,24}$ However, only about seventeen percent and twenty five percent of health facilities had some form of data analysis from the respective groups; this is similar to findings by Abubakar et al in Kaduna State, ${ }^{13}$ but lower than the findings in Tanzania by Mghamba et al. ${ }^{24}$ The present study findings depicts poor data analysis which may be due to the absence of standardized data analysis procedures.

Following the intervention, there was improvement in knowledge of IDSR among the health care workers in both LGAs, but the improvement in the study group was more pronounced than in the control. The mean and standard deviation of knowledge scores increased for the study group from a baseline level of $28.7 \pm 9.7$ to $51.1 \pm 11.9$ after intervention. While, the aggregate knowledge scores of IDSR in the study group increased from $38.0 \%$ at base-

Table 4. Comparison of good knowledge of IDSR at baseline and post-intervention among study and control groups.

\begin{tabular}{lcccc}
\hline PHC workers knowledge on IDSR & Study group frequency (\%) & Control group frequency (\%) & Total \\
Baseline & $62 / 163(38.0)$ & $64 / 163(39.3)$ & 126 & 187 \\
Post intervention & $124 / 151(82.1)$ & $63 / 153(41.2)$ & 313 \\
\hline Total $\quad 186$ & 127 & 3 & \\
\hline
\end{tabular}

$\chi^{2}=8.44 \mathrm{df}=1, \mathrm{P}=0.0037$

Table 5. Comparison of good practices on IDSR at baseline and post-intervention among participants.

\begin{tabular}{lccc} 
PHC workers knowledge on IDSR & Study group frequency (\%) & Control group frequency (\%) & Total \\
Baseline & $42 / 163(25.8)$ & $46 / 163(28.2)$ & 88 \\
Post intervention & $96 / 151(63.6)$ & $55 / 153(35.9)$ & 151 \\
\hline Total & 138 & 101 & 313 \\
\hline
\end{tabular}

$\chi^{2}=5.09 \mathrm{df}=1, \mathrm{P}=0.024$ 
line to $82.1 \%$ at post-intervention, that of the control group marginally increased from $39.3 \%$ at baseline to $41.2 \%$ at postintervention.

Furthermore, the IDSR practice had significantly increased in the study group on some practice components that include; conducting laboratory investigations for IDSR priority diseases, reporting of zero case for epidemic prone diseases, sending feedback to catchment population and use of appropriate forms in reporting IDSR diseases: the difference was found to be statistically significant $(\mathrm{P}<0.05)$. Meanwhile, the mean and standard deviation of practice scores increased for the study group from a baseline level of $6.43 \pm 1.25$ to $16.37 \pm 3.86$ after intervention. While, the aggregate good practice scores of IDSR in the study group increased from $25.8 \%$ at baseline to $63.6 \%$ at post-intervention. While that of the control group, marginally increased from $28.2 \%$ at baseline to $35.9 \%$ at post-intervention.

The observed increase in knowledge and practices of health workers in the study group can be attributed to the training and supportive supervision conducted.

\section{Conclusions}

The significant increase in knowledge and practices of IDSR among PHC workers in the study as compared to those in the control group showed that training and supportive supervision as an intervention directed at health workers can significantly increase their knowledge and practices on IDSR. It was recommended that, there should be regular training and retraining of health workers responsible for data generation, collection and transmission in health facilities on IDSR by State Primary Health Care Management Board in collaboration with development partners.

\section{References}

1. World Health Organization. Overview of the framework for monitoring and evaluating surveillance and response systems for communicable diseases. Wkly Epidemiol Rec 2004;79:322-6

2. World Health Organization. Disease surveillance-WHO's role: Wkly Epidemiol Rec 1998;73:333-4.

3. World Health Organization. Protocol for the Assessment of National Communicable Disease Surveillance and Response Systems: Guidelines for Assessment Teams. World Health Organization, Geneva; 2001.

4. Epidemiology Division. National Technical Guidelines for Integrated Diseases Surveillance and Response. Volume I. Federal Ministry of Health, Abuja; June 2001.

5. Epidemiology Division. National Policy on Integrated Diseases Surveillance and Response. Federal Ministry of Health, Abuja; September 2005.

6. Technical Guidelines for Integrated Disease Surveillance and Response in African Region October, African Regional Office of WHO; 2010.

7. Franco LM, Setzer J, Banke K. Improving performance of IDSR at district and facility levels: experience in Tanzania and Ghana in making IDSR operational. Bethesda, MD: The Partners for Reform plus Project. Abt Associates; 2006.

8. PAHO. An integrated approach to communicable disease surveillance. PAHO Epidemiol Bull 2000;21:1-4.

9. Teutsch SM, Thacker SB. Planning a public health surveillance system. PAHO Epidemiol Bull 1995;16:1-6.
10. Division of communicable Diseases Control, World Health Organization Regional Office for Eastern Mediterranean Newsletter, November 2002.

11. African Regional Office of WHO. Synthesis report on the Implementation of Integrated Diseases Surveillance and Response in Africa and Eastern Mediterranean, May 2003

12. Ofili AN, Ugwu EN, Zirebe A, Richards R, Salami S. Knowledge of disease notification among doctors in government hospitals in Benin City, Edo State, Nigeria. Public Health 2003;117:214-7.

13. Abubakar AA, Idris SH, Sabitu K, et al. Emergency preparedness and capability to identify outbreaks: A case of Sabon Gari Local Government Area, Kaduna State. Ann Niger Med 2010;4:21-7.

14. Nnebue CC, Onwasigwe CN, Ibeh CC, Adogu P. Effectiveness of data collection and information transmission process for disease notification in Anambra State, Nigeria. Niger J Clin Pract 2013;16:483-9.

15. Bawa SB, Olumide EA. The effect of training on the reporting of notifiable diseases among health workers in Yobe State, Nigeria. Niger Postgrad Med J 2005;12:1-5.

16. Nicolas N, Angela MCR, Dominic L, Sylvestre RM. Meningitis Serogroup W135 Outbreak, Burkina Faso, 2002. Emerg Infect Dis 2007;13:6.

17. Bawa SB, Olumide EA, Umar US. The knowledge, attitude and practices of the reporting of notifiable diseases among health workers in Yobe State, Nigeria. Afr J Med Sci 2003;32:49-53.

18. Rhode J. Supportive Supervision to Improve Integrated Primary Health Care. MSH Occasional Paper 2006;2:3-4.

19. Manual for Comprehensive Supportive Supervision and mentoring on HIV and AIDS health services. The United Republic of Tanzania Ministry of Health and Social Welfare; March 2010.

20. Dairo MD, Bamidele JO, Adebimpe WO. Disease surveillance and reporting in two Southwestern states in Nigeria: Logistic challenges and prospects. J Publ Health Epidemiol 2010;2: 125-9.

21. Bawa SB, Umar US. The functional status of diseases surveillance and notification system at the local government level in Yobe State, Nigeria. Afr J Med Sci 2003;32:49-55.

22. Nnebue CC, Onwasigwe CN, Adogu POU, Ugochukwu UO. Awareness and knowledge of disease surveillance and notification by health-care workers and availability of facility records in Anambra State, Nigeria. Niger J Clin Pract 2013;16:471-7.

23. WHO. Assessment of the national communicable disease surveillance and response system, Ethiopia. Bull WHO 2001;76:9-16.

24. Mghamba JM, Mboera LEG, Krekamo W, et al. Challenges of implementing an IDSR strategy using the current Health Management Information System in Tanzania. Tanz Health Res Bull 2004;6:57-63.

25. Hsiu-Fen et al. Private Doctors' practices, knowledge, and attitude to reporting of communicable diseases: a national survey in Taiwan. BMC Infectious Diseases. 2009; 9(11) $102-103$.

26. Sahal N, Reintjes R, Mahgoub AE, Aro AR. Assessment of core activities and supportive functions of the communicable diseases surveillance system in Khartoum state, Sudan for the years 2005 - 2007. East Med J Health 2010;16:1204-10.

27. Nsubuga P, McDonnell S, Perkins B, et al. Polio eradication initiative in Africa: influence on other infectious disease surveillance development. BMC Publ Health 2002;2:1-6. 